\title{
Predictors of Unfavorable Outcomes in Patients with Atrial Fibrillation and Concomitant Heart Failure with Different Ejection Fractions: RIF-CHF Register One-Year Follow-Up
}

\author{
Igor Zhirov (D), ${ }^{1}$ Natalia Safronova, ${ }^{1}$ Yulia Osmolovskaya, ${ }^{1}$ Alina Alshevskaya, ${ }^{2}$ \\ Andrey Moskalev, ${ }^{2}$ and Sergey Tereshchenko ${ }^{1}$ \\ ${ }^{1}$ National Medical Research Center for Cardiology, Moscow, Russia \\ ${ }^{2}$ Biostatistics and Clinical Trials Center, Novosibirsk, Russia \\ Correspondence should be addressed to Igor Zhirov; igor.v.zhirov@mail.ru
}

Received 29 January 2019; Accepted 2 April 2019; Published 15 May 2019

Academic Editor: Robert Chen

Copyright (c) 2019 Igor Zhirov et al. This is an open access article distributed under the Creative Commons Attribution License, which permits unrestricted use, distribution, and reproduction in any medium, provided the original work is properly cited.

\begin{abstract}
Background. Atrial fibrillation (AF) and heart failure (HF) are tightly interrelated. The concurrence of these pathologies can aggravate the pathological process. The geographic and ethnic characteristics of patients may significantly affect the efficacy of different types of therapy and patients' compliance. The objective of this study was to analyze how the features of the course of the diseases and management of HF + AF influence the clinical outcomes. Methods. The data of 1,003 patients from the first Russian register of patients with chronic heart failure and atrial fibrillation (RIF-CHF) were analyzed. The endpoints included hospitalization due to HF worsening, mortality, thromboembolic events, and hemorrhage. Predictors of unfavorable outcomes were analyzed separately for patients with $\mathrm{HF}$ and preserved ejection fraction $(\mathrm{AF}+\mathrm{HFpEF})$, midrange ejection fraction $(\mathrm{AF}+\mathrm{HFmrEF})$, and reduced ejection fraction $(\mathrm{AF}+\mathrm{HFrEF})$. Prevalence of $\mathrm{HF}+\mathrm{AF}$ and compliance with long-term treatment of this pathology during one year were evaluated for each patient. Results. The study involved $39 \%$ AF $+\mathrm{HFpEF}$ patients, $15 \%$ $\mathrm{AF}+\mathrm{HFmrEF}$ patients, and 46\% AF + HFrEF patients. AF + HFpEF patients were significantly older than patients in two other groups ( $40.6 \%$ of patients were older than $\geq 75$ years vs. $24.8 \%$, respectively, $p<0.001$ ) and had the lowest rate of prior myocardial infarctions $(25.3 \%$ vs. $46.1 \%, p<0.001)$ and the lowest adherence to rational therapy of $\mathrm{HF}(27.4 \%$ vs. $47.1 \%, p<0.001)$. $\mathrm{AF}+\mathrm{HFmrEF}$ patients had the highest percentage of cases of HF onset after AF $(61.3 \%$ vs. $49.2 \%$ in other patient groups, $p=0.021)$. Among patients with AF $+\mathrm{HFrEF}$, there was the highest percentage of males $(74.2 \% \mathrm{vs.} 41 \%$ in other patient groups, $p<0.001)$ and the highest percentage of ever-smokers (51.9\% vs. $29.4 \%$ in other patient groups, $p<0.001$ ). A total of $57.2 \%$ of patients were rehospitalized for decompensation of chronic heart failure within one year; the risk was the highest for $\mathrm{AF}+\mathrm{HFmrEF}$ patients $(66 \%, p=0.017)$. Reduced ejection fraction was associated with the increased risk of cardiovascular mortality $(15.5 \%$ vs. $5.4 \%$ in other patient groups, $p<0.001)$ rather than ischemic stroke $(2.4 \%$ vs. $3 \%, p=0.776)$. Patients with $\mathrm{AF}+\mathrm{HFpEF}$ had lower risk to achieve the combination point (stroke $+\mathrm{IM}+\mathrm{CV}$ death) as compared to patients with $\mathrm{AF}+\mathrm{HFmrEF}$ and $\mathrm{AF}+\mathrm{HFrEF}(12.7 \%$ vs. $22 \%$ and $25.5 \%, p<0.001)$. Regression logistic analysis revealed that factors such as demographic characteristics, disease severity, and administered treatment had different effects on the risk of unfavorable outcomes depending on ejection fraction group. The clinical features and symptoms were found to be significant risk factors of cardiovascular mortality in AF + HFmrEF, while therapy characteristics were not associated with it. Conclusions. Each group of patients with different ejection fractions is characterized by its own pattern of factors associated with the development of unfavorable outcomes. The demographic and clinical characteristics of patients with midrange ejection fraction demonstrate that these patients need to be studied as a separate cohort.
\end{abstract}




\section{Introduction}

Atrial fibrillation (AF), the most frequently encountered sustained cardiac arrhythmia, is the key risk factor for transient ischemic attack (TIA), stroke, and heart failure [1]. Its prevalence goes up with age, and population in Russia is aging nowadays. Heart failure (HF) is induced by structural and/or functional cardiac abnormalities and results in decreased cardiac pump function [2]. Atrial fibrillation and heart failure are closely interrelated $[3,4]$. There currently is lack of understanding of the association between AF and heart failure with preserved ejection fraction (HFpEF); however, the clinical aspects seem to be rather important [5]. Comorbidity of atrial fibrillation and heart failure (AF + HF) is frequently observed because of the high prevalence of each disease entity, as well as due to shared risk factors and synergistic pathophysiology [6]. As the global population ages, the burden of both disease entities will be getting stronger over time [5]. Since these disease states have similar mechanisms, AF and HF tend to coexist [7-11]. One of the key features of their comorbidity is that each disease entity can trigger and aggravate the course of the other condition. The risk of thromboembolism in patients with atrial fibrillation becomes higher if they have such comorbidities as ischemic heart disease, hypertension, and diabetes [1]. The coexisting $\mathrm{AF}+\mathrm{HF}$ increase the risk of thromboembolic complications, stroke in particular [1], and may deteriorate the cardiac function. In its turn, it results in aggravation of HF symptoms, thus leading to a self-perpetuating vicious circle [7]. Depending on whether AF or HF is the underlying condition, patient groups differ rather significantly in terms of outcomes and the required therapeutic approach. A patient who developed $\mathrm{HF}$ after AF has a more favorable prognosis [12] than a patient who had $\mathrm{HF}$ prior to $\mathrm{AF}$ $[13,14]$, probably because AF is a marker of severe course of the disease and can deteriorate the cardiac function [7]. Even this difference alone attests to significant heterogeneity observed in the total cohort of these patients. However, there are other important parameters subdividing patients with $\mathrm{AF}+\mathrm{HF}$ into the fundamentally different groups.

According to the current clinical practice guidelines for managing patients with chronic heart failure (CHF) (2016), heart failure is divided into three clinical subtypes: HF with a preserved ejection fraction (HFpEF: $\mathrm{EF} \geq 50 \%$ ), HF with a midrange ejection fraction (HFmrEF: $40 \leq \mathrm{EF}<49 \%$ ), and $\mathrm{HF}$ with a reduced ejection fraction (HFrEF: EF < 40\%) [7]. These patient cohorts strongly differ in terms of a number of parameters, from the epidemiology and etiology to the current severity and treatment strategies. Many questions regarding the differential treatment strategy are yet to be solved. One of the reasons is that our knowledge of HFpEF and HFmrEF is limited, and the data about these conditions have mainly been obtained from retrospective studies or post hoc analyses of randomized trials [7, 15]. Over the past 2 years, there has been a trend to conduct studies in isolated subgroups of patients having a certain ejection fraction [16-19]. This makes study groups more homogeneous and allows one to draw relevant conclusions. However, studies of this type are not devoid of drawbacks. The most fundamental one is that it is impossible to compare patients with different ejection fractions who are similar in nonmodifiable risk factors, such as area of residence, ethnicity, environment, climate, and family history. This fact prevents evaluation of the contribution of modifiable risk factors (lifestyle, dietary habits, current therapy, and prior therapy) to development and course of the disease. Simultaneous searching for intergroup similarities and differences needs to be conducted to understand the general principles of pathogenesis and the course of comorbid AF + AHF. One of the advantages of nationwide cohort studies as compared to narrowly focused prospective studies having strict inclusion criteria regarding the ejection fraction is that all three patient subtypes are included and can be compared.

There is a gap in understanding of the overall clinical pattern of the course of $\mathrm{CHF}+\mathrm{AF}$ comorbidity and in selection of the optimal treatment strategies; so, it is very important to perform cross-sectional studies to fill this gap. The high prevalence of $\mathrm{AF}+\mathrm{CHF}$ offers a unique opportunity for the researchers worldwide both to conduct largescale prospective randomized clinical trials [20-27] and to collect the populationwide data using registries [1, 2, 28-31]. Each of these designs has its own advantages and drawbacks. Randomized clinical trials allow one to use the "refined" patient subgroups to answer a specific question regarding the treatment approach. Nation- and regionwide cohort studies make it possible to reveal the overall regularities in etiology and pathogenesis, as well as to demonstrate the realworld situation.

Our study was aimed to analyze how the features of the course of diseases and management of $\mathrm{CHF}+\mathrm{AF}$ influence the clinical outcomes and collecting the data on compliance with clinical guidelines and on the long-term prevalence of this condition in Russia.

\section{Patients and Methods}

2.1. Study Design, Patient Selection, and Ethical Considerations. The analysis was conducted using the data retrieved from the Russian registry of patients with chronic heart failure and atrial fibrillation (RIF-CHF) that involved the data obtained in a multicenter prospective observational study in patients with $\mathrm{CHF}+\mathrm{AF}$ (clinicaltrials.gov NCT02790801). Patients were recruited for survey participation at 30 medical centers in 21 provinces of the Russian Federation over the period between February 2015 and January 2016. The patients were selected on a competitive continuous basis. The planned total number of patients to be recruited was $\geq 1,000$. The recruitment was stopped once 1,003 patients had been selected.

All patients had a confirmed diagnosis of $\mathrm{CHF}+\mathrm{AF}$ comorbidity. The diagnosis of CHF was made according to the local Russian guidelines and corresponded to the ESC 2012 HF Guidelines criteria and ESC 2012 Update of the Guidelines for the Management of Atrial Fibrillation. The division into ejection fraction groups was conducted with allowance for the 2016 amendments to the Guidelines.

The inclusion criteria were as follows: 
(1) Age $>18$ years

(2) Documented symptomatic chronic heart failure for at least 3 months prior to screening in accordance with the following criteria:

(a) no additional laboratory verification of the diagnosis is needed at LVEF $\leq 40 \%$

(b) at LVEF $>40 \%$, the NT-proBNP level $\geq 300 \mathrm{pg} / \mathrm{ml}$ or $\mathrm{BNP}$ level $\geq 100 \mathrm{pg} / \mathrm{ml}$

(3) Hemodynamically stable nonvalvular atrial fibrillation

The exclusion criteria were as follows: transient ischemic attack within 3 days before enrollment; stroke during 14 days before enrollment; myocardial infarction within 14 days before enrollment; thromboembolic complications or thrombosis within 14 days before enrollment; heart failure because of valvular pathology; heart failure induced by infectious agents or infiltrative diseases; alcohol consumption; use of psychoactive drugs; peripartum heart disease; transient conditions; planned heart transplantation; implantation of biventricular pacemaker within 28 days before enrollment; any severe condition limiting patient's life to less than 3 months; HIV infection; alcohol consumption or intake of psychoactive drugs; participation in any experimental study within 30 days before enrollment; and patient being not ready to be contacted by telephone at the end of the follow-up period.

The survey was conducted in compliance with the Good Clinical Practice ensuring that the design, implementation, and communication of data are reliable; that patients' rights are protected; and that the integrity of subjects is maintained by the confidentiality of their data. The study was approved by the Local Ethics Committee of the Federal State Budget Scientific Institution "Research Institute of Cardiology" and registered at clinicaltrials.gov (no. NCT02790801). All patients provided written informed consent in accordance with the Declaration of Helsinki, which included their consent for their data to be analyzed and presented.

2.2. Data Collection: Baseline. Patients' life and past medical histories were collected at admission. Parameters to be collected and documented were as follows:

(i) General and demographic characteristics: date of birth, gender, educational status, occupation, residential region, smoking status, dietary habits, weight, height, and physical activity level

(ii) Features and course of the disease in the past: dates when the patient was diagnosed with $\mathrm{CHF}$ and $\mathrm{AF}$, predominant cardiac diagnosis, frequency of hospitalization over the past year, and past history of surgeries

(iii) The current disease status: the reason for the current hospital admission (scheduled follow-up examination, decompensated heart failure, and surgical treatment), symptoms and signs, and blood pressure; instrumented test values (ECG, echocardiography); presence and severity of aortic and mitral regurgitation; and blood chemistry test

(iv) Current treatment and patient's response to it: all drugs administered to treat $\mathrm{CHF}$ and AF; compliance with the treatment schedules according to the local and international guidelines; and efficacy of heart rate control for patients with permanent atrial fibrillation (maintaining the heart rate at $<100 \mathrm{bpm}$ )

(v) Concomitant diseases

(vi) Family history of hypertension, AF, and early-onset IHD

The clinical and laboratory data for each patient were collected 6 and 12 months after study enrollment.

2.3. Data Collection: Endpoints. The primary endpoint was hospitalization due to worsening of heart failure. HF hospitalization was defined as an overnight (or longer) stay in a hospital, with HF being the primary reason.

Secondary endpoints were death from a cardiovascular event (CV mortality), thromboembolic events (overall and for each category), and bleeding (ISTH major or CRNM). The time of event onset was documented for the endpoints. If possible, the follow-up was continued for 12 months.

2.4. Data Collection: Therapy Adherence. Therapy adherence was evaluated by a direct survey. At each of the three visits, patients were asked to provide information regarding the therapy they were currently receiving, as well as the therapy they had been receiving over the previous 6 months.

2.5. Statistical Analysis. Descriptive statistics were presented as absolute frequencies or medians with the interquartile range. The Mann-Whitney $U$ test, or Pearson's $\chi 2$ test, or Fisher's exact test and nonparametric Kruskal-Wallis test by rank and median multiple comparisons were used depending on type of the data being processed. The Kaplan-Meier model was employed to analyze the achievement of target indicators. All the reported $p$ values were based on two-tailed tests of significance; the $p$ values $<0.05$ were regarded as statistically significant. STATISTICA 7.0 software (StatSoft, USA) and RStudio software version 1.0.136 (Free Software Foundation, Inc., USA) with $\mathrm{R}$ packages version 3.3.1 ( $\mathrm{R}$ Foundation for Statistical Computing, Austria) were used for the analyses.

\section{Results}

3.1. Baseline Characteristics. The survey included 1,003 patients with AF $+\mathrm{HF}$. Almost half of them (46.5\% of patients) had heart failure with reduced ejection fraction (AFHFrEF); 38.6 and 15\% of patients had heart failure with preserved (AF-HFpEF) and midrange (AF-HFmrEF) ejection fractions, respectively. The data on patient characteristics at baseline are summarized in Table 1-3. 
TABLE 1: Demographic and anamnestic characteristics of patients included in the study.

\begin{tabular}{|c|c|c|c|c|c|}
\hline Parameters & $\begin{array}{l}\text { Total cohort } \\
(n=1003)\end{array}$ & $\begin{array}{c}\text { AF-HFpEF } \\
(n=387)\end{array}$ & $\begin{array}{l}\text { AF-HFmEF } \\
(n=150)\end{array}$ & $\begin{array}{l}\text { AF-HFrEF } \\
(n=466)\end{array}$ & $p$ level \\
\hline \multicolumn{6}{|l|}{ Demography and habits } \\
\hline Age, years & $68(60: 76)$ & $72(63: 78)$ & $67(58: 75)$ & $66(58: 75)$ & $<0.001$ \\
\hline The proportion of patients $\geq 65$ years of age & $589(58.7 \%)$ & $270(69.8 \%)$ & $82(54.7 \%)$ & $237(50.9 \%)$ & $<0.001$ \\
\hline The proportion of patients $\geq 75$ years of age & $310(30.9 \%)$ & $157(40.6 \%)$ & $38(25.3 \%)$ & $115(24.7 \%)$ & $<0.001$ \\
\hline Female sex, $n(\%)$ & $437(43.6 \%)$ & $253(65.4 \%)$ & $64(42.7 \%)$ & $120(25.8 \%)$ & $<0.001$ \\
\hline Body mass index $\geq 30$ & $360(35.9 \%)$ & $147(38 \%)$ & $62(41.3 \%)$ & $151(32.4 \%)$ & 0.076 \\
\hline $\begin{array}{l}\text { Low level of physical activity (exercise less } \\
\text { than } 30 \mathrm{~min} / \text { day, no more than } 3 \text { times/week) } \\
\text { Smoking }\end{array}$ & $570(56.8 \%)$ & $191(49.4 \%)$ & $96(64 \%)$ & $283(60.7 \%)$ & $<0.001$ \\
\hline Never & $603(60.1 \%)$ & $295(76.2 \%)$ & $84(56 \%)$ & $224(48.1 \%)$ & $<0.001$ \\
\hline Quit smoking & $216(21.5 \%)$ & $53(13.7 \%)$ & $38(25.3 \%)$ & $125(26.8 \%)$ & \\
\hline Active smoker & $184(18.3 \%)$ & $39(10.1 \%)$ & $28(18.7 \%)$ & $117(25.1 \%)$ & \\
\hline \multicolumn{6}{|l|}{ Comorbidities and pathologies } \\
\hline Hypertension, fact & $653(65.1 \%)$ & $263(68 \%)$ & $108(72 \%)$ & $282(60.5 \%)$ & 0.012 \\
\hline Hypertension, duration, years & $14(10: 20)$ & $13(10: 20)$ & $10(7.5: 20)$ & $15(10: 20)$ & 0.916 \\
\hline Ischemic heart disease & $686(68.4 \%)$ & $271(70 \%)$ & $107(71.3 \%)$ & $308(66.1 \%)$ & 0.336 \\
\hline Diabetes mellitus & $247(24.6 \%)$ & $89(23 \%)$ & $38(25.3 \%)$ & $120(25.8 \%)$ & 0.632 \\
\hline Previous stroke/TIA & $158(15.8 \%)$ & $58(15 \%)$ & $22(14.7 \%)$ & $78(16.7 \%)$ & 0.747 \\
\hline Previous myocardial infarct & $382(38.1 \%)$ & $98(25.3 \%)$ & $61(40.7 \%)$ & $223(47.9 \%)$ & $<0.001$ \\
\hline Vascular disease & $502(50 \%)$ & $157(40.6 \%)$ & $74(49.3 \%)$ & $271(58.2 \%)$ & $<0.001$ \\
\hline Abnormal renal function & $145(14.5 \%)$ & $45(11.6 \%)$ & $24(16 \%)$ & $76(16.3 \%)$ & 0.123 \\
\hline Abnormal liver function & $101(10.1 \%)$ & $12(3.1 \%)$ & $20(13.3 \%)$ & $69(14.8 \%)$ & $<0.001$ \\
\hline \multicolumn{6}{|l|}{ Family history } \\
\hline $\begin{array}{l}\text { Family history of coronary artery disease early } \\
\text { development }\end{array}$ & $230(22.9 \%)$ & $78(20.2 \%)$ & $43(28.7 \%)$ & $109(23.4 \%)$ & 0.106 \\
\hline Hypertension in relatives & $516(51.4 \%)$ & $231(59.7 \%)$ & $84(56 \%)$ & $201(43.1 \%)$ & $<0.001$ \\
\hline
\end{tabular}

TABLE 2: Clinical characteristics of AF + HF severity.

\begin{tabular}{|c|c|c|c|c|c|}
\hline Parameters & $\begin{array}{l}\text { Total cohort } \\
(n=1003)\end{array}$ & $\begin{array}{l}\text { AF-HFpEF } \\
(n=387)\end{array}$ & $\begin{array}{c}\text { AF-HFmEF EF } \\
\quad(n=150)\end{array}$ & $\begin{array}{l}\text { AF-HFrEF } \\
(n=466)\end{array}$ & $p$ level \\
\hline CHF duration, months & $40(12: 96)$ & $48(22.5: 100)$ & $36(12: 72)$ & $48(12: 96)$ & 0.265 \\
\hline AF duration, months & $48(15: 96)$ & $50(24: 108)$ & $38(12: 89)$ & $40(12: 96)$ & 0.042 \\
\hline Age at AF debut & $62(54.25: 70.7)$ & $64.4(57.9: 72.6)$ & $60.8(50.88: 70.22)$ & $59.9(51.5: 68.55)$ & $<0.0001$ \\
\hline Age at HF debut & $62.1(54.7: 70.1)$ & $64(57.5: 72.9)$ & $61.65(54.15: 70.3)$ & $60.9(52.9: 67.8)$ & $<0.0001$ \\
\hline AF debuted after HF & $478(47.7 \%)$ & $197(50.9 \%)$ & $58(38.7 \%)$ & $223(47.9 \%)$ & 0.039 \\
\hline \multicolumn{6}{|l|}{ Type of AF } \\
\hline Paroxysmal & $276(27.5 \%)$ & $144(37.2 \%)$ & $30(20 \%)$ & $102(21.9 \%)$ & $<0.001$ \\
\hline Nonparoxysmal & $727(72.5 \%)$ & $243(62.8 \%)$ & $120(80 \%)$ & $364(78.1 \%)$ & \\
\hline \multicolumn{6}{|l|}{ Blood pressure } \\
\hline Systolic & $130(120: 140)$ & $140(130: 150)$ & $130(120: 140)$ & $120(110: 140)$ & $<0.0001$ \\
\hline Diastolic & $80(70: 90)$ & $80(80: 90)$ & $80(70: 90)$ & $80(70: 80)$ & 0.01 \\
\hline \multicolumn{6}{|l|}{ Heart rate } \\
\hline Rate (beats/min) & $84(70: 100)$ & $80(68: 90)$ & $85.5(75.25: 90.75)$ & $84(75: 97)$ & 0.226 \\
\hline Rate $>100, n(\%)$ & $327(32.6 \%)$ & $103(26.6 \%)$ & $56(37.3 \%)$ & $168(36.1 \%)$ & 0.005 \\
\hline $\begin{array}{l}\text { CHA2DS2-VASc score, Me } \\
\text { (IQR) }\end{array}$ & $4(3: 5)$ & $5(3: 6)$ & $4(3: 5)$ & $4(2: 5)$ & $<0.001$ \\
\hline HAS-BLED, Me (IQR) & $3(2: 4)$ & $5(3: 6)$ & $4(3: 5)$ & $4(2: 5)$ & $<0.001$ \\
\hline
\end{tabular}

Patients with preserved ejection function were significantly older (median age, 72 years (IQR $63: 78$ ) vs. 67 years $(58: 75)$ in the AF-HFmrEF group and 66 years $(58: 75)$ in the AF-HFrEF group). The percentage of women was the highest $(65.4 \%)$ in the AF-HFpEF group and the lowest in the AF-HFrEF group (25.8\%). Approximately 75\% of patients with AF-HFpEF had never smoked, while only $50 \%$ of patients in the AF-HFmEF and AF-HFrEF groups were never-smokers $(p=0.003)$.
The groups were comparable in terms of previous history of stroke $(15,14.7$, and $16.7 \%$ in the AF-HFpEF, AFHFmrEF, and AF-HFrEF groups, respectively; $p=0.747$ ) and significantly differed in terms of their history of infarction (25.3, 40.7, and 47.9\%, respectively; $p<0.001$ ). While in the AF-HFpEF and AF-HFrEF subgroups, patients developing AF already had $\mathrm{CHF}$ (50.9 and 47.9\%, respectively), and the percentage of these patients in the AFHFmrEF group was significantly lower (38.7\%; $p=0.039)$. 
TABLE 3: The results of laboratory tests and instrumental examinations of patients at the time of inclusion with the study.

\begin{tabular}{|c|c|c|c|c|c|}
\hline Parameters & $\begin{array}{c}\text { Total cohort } \\
(n=1003)\end{array}$ & $\begin{array}{c}\text { AF-HFpEF } \\
(n=387)\end{array}$ & $\begin{array}{c}\text { AF-HFmEF EF } \\
\quad(n=150)\end{array}$ & $\begin{array}{c}\text { AF-HFrEF } \\
(n=466)\end{array}$ & $p$ level \\
\hline Left ventricular ejection fraction, $\%$ & $40(35: 58)$ & $60(55: 65)$ & $43(40: 46)$ & $34(29: 37)$ & $<0.0001$ \\
\hline Aortic insufficiency & $410(50.9 \%)$ & $166(42.9 \%)$ & $57(38 \%)$ & $187(40.1 \%)$ & 0.529 \\
\hline Mitral insufficiency & $805(80.3 \%)$ & $310(80.1 \%)$ & $123(82 \%)$ & $372(79.8 \%)$ & 0.841 \\
\hline Pulmonary insufficiency & $367(36.6 \%)$ & $135(34.9 \%)$ & $52(34.7 \%)$ & $180(38.6 \%)$ & 0.459 \\
\hline Tricuspidal insufficiency & $766(76.4 \%)$ & $284(73.4 \%)$ & $121(80.7 \%)$ & $361(77.5 \%)$ & 0.153 \\
\hline $\begin{array}{l}\text { Left ventricular end diastolic } \\
\text { dimension, } \mathrm{cm}\end{array}$ & $5.6(5: 6.3)$ & $5(4.6: 5.3)$ & $5.9(5.3: 6.38)$ & $6.2(5.7: 6.91)$ & $<0.0001$ \\
\hline $\begin{array}{l}\text { Left ventricular end systolic dimension, } \\
\mathrm{cm}\end{array}$ & $4.1(3.2: 5.05)$ & $3.1(3: 3.6)$ & $4.5(4: 5)$ & $5(4.5: 5.7)$ & $<0.0001$ \\
\hline Cardiothoracic index $(\%)$ & $57(54: 62)$ & $56.5(53: 61)$ & $60(55: 63)$ & $57(55: 63)$ & 0.086 \\
\hline $\begin{array}{l}\text { Ventricular extrasystoles, total } \\
\text { Laboratory analysis }\end{array}$ & $122(17: 775.5)$ & $40(8: 327.25)$ & $79(13: 1163)$ & $277(78.5: 1319)$ & 0.029 \\
\hline $\mathrm{BNP}$ & $300(158.25: 602.48)$ & $\begin{array}{l}245.5(152.25: \\
429.75)\end{array}$ & $317.5(142.25: 507.15)$ & $\begin{array}{l}490.5(186.52: \\
941.75)\end{array}$ & 0.008 \\
\hline NT-proBNP & $536(349.5: 1085)$ & $562(425: 968)$ & $338(327: 353.5)$ & $1484(289: 2866)$ & 0.01 \\
\hline International normalised ratio & $1.27(1.04: 2)$ & $1.15(1: 1.67)$ & $1.29(1.1: 1.9)$ & $1.42(1.1: 2.08)$ & 0.019 \\
\hline D-dimer & $1.2(0.35: 4.75)$ & $1.38(0.22: 109)$ & $2(0.24: 187)$ & $1.1(0.49: 1.65)$ & 0.048 \\
\hline
\end{tabular}

CHF duration was comparable between the groups, while the oldest age of CHF onset was observed for the AF-HFpEF group (64 years; IQR $57.5: 72.9$ ). Regardless of the oldest age of AF onset (64.4 years; IQR 57.9:72.6), patients in the AFHFpEF subgroup had the longest duration of $\mathrm{AF}$ (50 months; IQR $24: 108$ ). The percentage of patients with paroxysmal AF in the AF-HFpEF group was almost twice as high as that in the other two groups $(37.2 \%$ vs. $20 \%$ in the AF-HFmrEF and $21.9 \%$ in the AF-HFrEF group). The rate control strategy was most effective in the AF-HFpEF group: the heart rate was $>100 \mathrm{bpm}$ only in $26.6 \%$ of patients ( $p=0.005$ as compared to the other two groups). The groups differed in terms of risks of stroke and bleeding (Figure 1).

At baseline, the therapy differed significantly for patients in three subgroups (Table 4). Although the rate control strategy was prevailing in all the three groups, the percentage of patients treated using the rhythm control strategy was the lowest in the AF-HFpEF group (27.9\%) and the highest in the AF-HFpEF group (40.6\%) $(p<0.001)$. Chronic anticoagulant therapy was given to $79.3 \%$ of patients in the AF-HFmrEF group, $70.8 \%$ of patients in the AF-HFpEF group, and $63.3 \%$ of patients in the AF-HFrEF group $(p<0.001)$.

3.2. One-Year Follow-Up. During the one-year follow-up, $574(57.2 \%)$ patients were hospitalized because of decompensated CHF at least once. The maximum frequency of hospitalization was observed for the AF-HFmrEF group (66\%); the minimum, for the AF-HFpEF group (52.7\%) (Table 5; Figure 2).

In our cohort, the cardiovascular mortality rate went up as the EF decreased during the first year of follow-up: it was $4.1 \%$ in the AF-HFpEF group, $9.3 \%$ in the AF-HFmrEF group, and $15.5 \%$ in the AF-HFrEF group $(p<0.001)$. Significant variation in the dynamics of the mortality risk in groups depending on duration of $\mathrm{AF}$ and $\mathrm{HF}$ is shown in Figure 3.
The rate of all thromboembolic events in the total cohort was $3.4 \%$; the rate of ischemic stroke was $2.7 \%$. It is noteworthy that some patients (10 ( $1 \%$ of the total cohort) experienced two different thromboembolic events (e.g., stroke and PATE) during the follow-up period.

The myocardial infarction rate in the total cohort was 101 (10.1\%). Most of the infarctions were recurrent (96 out of 101). In patients with myocardial infarction experience, the rate of recurrent myocardial infarction was $25.1 \%$, while the rate of MI among patients having no history of MI was as low as $0.8 \%(p<0.001)$ during the follow-up. The significant variation in the myocardial infarction rate was also observed in the groups of patients with different ejection fractions: the AF-HFpEF patients were characterized by the lowest rate $(6.7 \%)$.

A total of 39 cases of bleeding (3.9\% of the total cohort) were documented during the follow-up: 13 (1.3\%) cases of gastrointestinal bleeding, $6(0.6 \%)$ cases of hemoptysis, 5 $(0.5 \%)$ cases of intracranial hemorrhage, and $14(1.5 \%)$ of cases of bleeding of other locations.

We conducted a search and analysis of factors for the primary and secondary points for three groups: AF-HFrEF, AF-HFmrEF, and AF-HFpEF. An analysis of factors significantly associated with outcomes led to the conclusion that the risk factors for adverse outcomes differ significantly for groups with different EFs (Table 6-8).

The number of specific signs of HF included pressure in the jugular veins, gallop rhythm, mixing the top of the jolt, wheezing in the lungs, and congestion in the lungs. Increase of venous pressure included jugular venous distention, pulmonary edema, pulmonary artery enlargement, and enlarged right heart. The number of typical symptoms of HF included dyspnea, fatigue, orthopnea, low effort tolerance, fatigue, edema, and apnoea. Bad habits included excess weight, diet, sedentary lifestyle, and hypercholesterolemia.

Among the demographic characteristics, gender was a significant predictor only in the HFpEF group. In this group, women were hospitalized significantly more often than men 


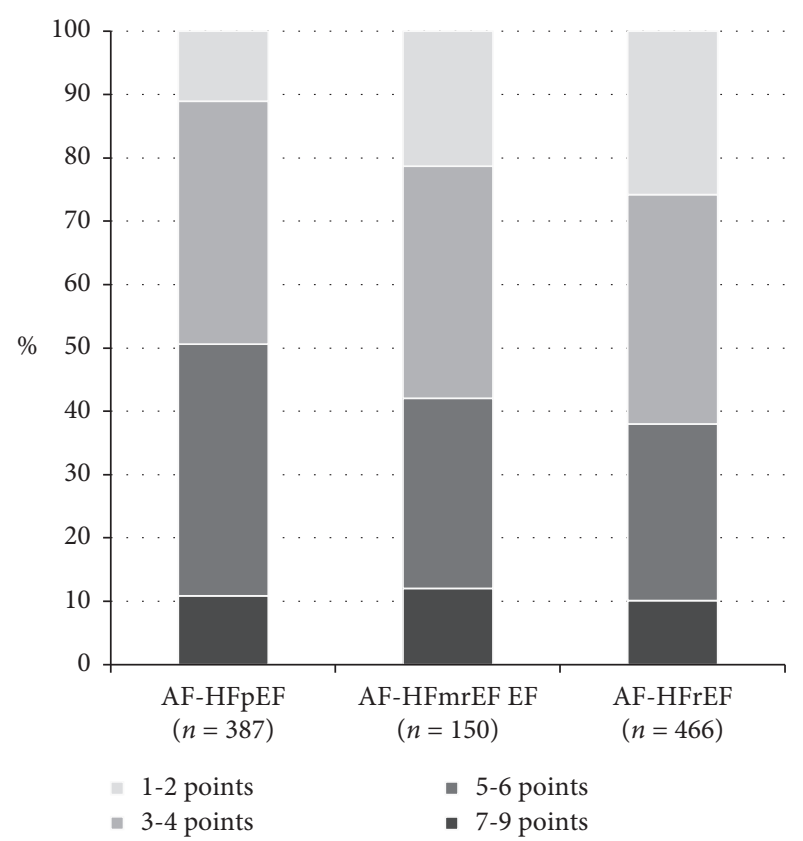

(a)

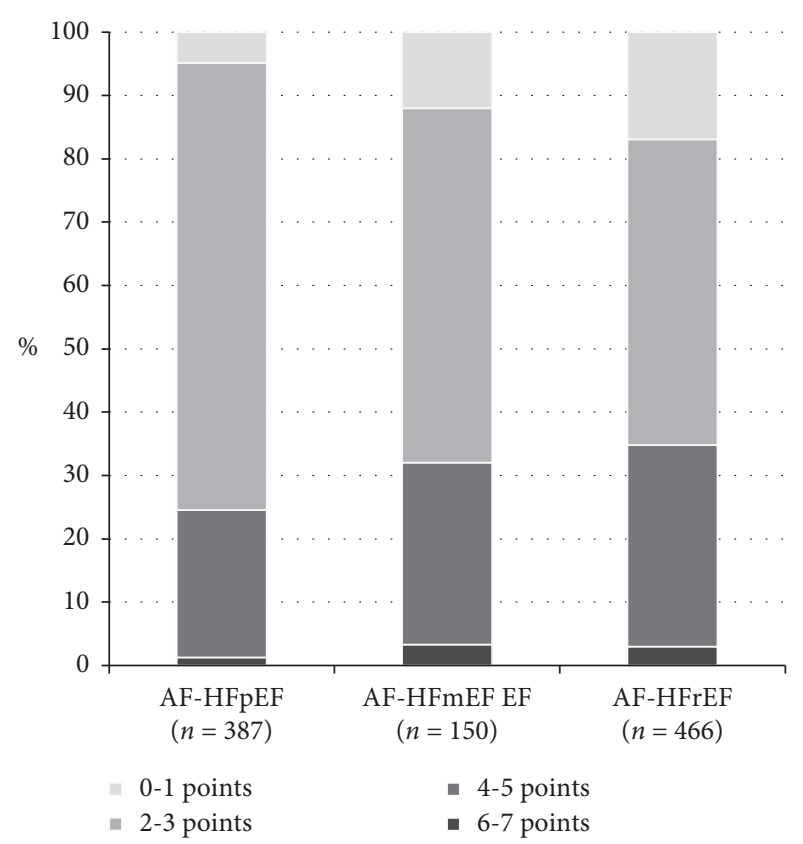

(b)

FIgURE 1: Risk assessment scales in studied subgroups. (a) CHA2DS2-VASc score. (b) HAS-BLED score.

TABLE 4: Medications for AF and CHF in studied groups.

\begin{tabular}{|c|c|c|c|c|c|}
\hline Parameters & $\begin{array}{l}\text { Total cohort } \\
(n=1003)\end{array}$ & $\begin{array}{l}\text { AF-HFpEF } \\
(n=387)\end{array}$ & $\begin{array}{l}\text { AF-HFmEF EF } \\
\quad(n=150)\end{array}$ & $\begin{array}{l}\text { AF-HFrEF } \\
(n=466)\end{array}$ & $p$ level \\
\hline \multicolumn{6}{|l|}{ Treatment strategy for $A F$} \\
\hline Rhythm control & $339(33.8 \%)$ & $157(40.6 \%)$ & $52(34.7 \%)$ & $130(27.9 \%)$ & \multirow{2}{*}{$<0.001$} \\
\hline Rate control & $664(66.2 \%)$ & $230(59.4 \%)$ & $98(65.3 \%)$ & $336(72.1 \%)$ & \\
\hline Rational therapy of $\mathrm{CHF}$ & $396(39.5 \%)$ & $106(27.4 \%)$ & $78(52 \%)$ & $212(45.5 \%)$ & $<0.001$ \\
\hline Beta-blocker & $830(82.8 \%)$ & $301(77.8 \%)$ & $136(90.7 \%)$ & $393(84.3 \%)$ & $<0.001$ \\
\hline Antiarrhythmic & $255(25.4 \%)$ & $123(31.8 \%)$ & $37(24.7 \%)$ & $95(20.4 \%)$ & $<0.001$ \\
\hline RAS antagonist & $218(21.7 \%)$ & $116(30 \%)$ & $27(18 \%)$ & $75(16.1 \%)$ & $<0.001$ \\
\hline Aldosterone blocker & $642(64 \%)$ & $164(42.4 \%)$ & $116(77.3 \%)$ & $362(77.7 \%)$ & $<0.001$ \\
\hline Statin & $606(60.4 \%)$ & $252(65.1 \%)$ & $89(59.3 \%)$ & $265(56.9 \%)$ & 0.046 \\
\hline Diuretic & $883(88 \%)$ & $332(85.8 \%)$ & $131(87.3 \%)$ & $420(90.1 \%)$ & 0.137 \\
\hline Digoxin & $360(35.9 \%)$ & $101(26.1 \%)$ & $53(35.3 \%)$ & $206(44.2 \%)$ & $<0.001$ \\
\hline $\begin{array}{l}\text { Oral anticoagulant (warfarin or/and } \\
\text { NOAC) }\end{array}$ & $688(68.6 \%)$ & $274(70.8 \%)$ & $119(79.3 \%)$ & $295(63.3 \%)$ & $<0.001$ \\
\hline Warfarin & $403(40.2 \%)$ & $157(40.6 \%)$ & $66(44 \%)$ & $180(38.6 \%)$ & 0.491 \\
\hline NOAC & $335(33.4 \%)$ & $140(36.2 \%)$ & $55(36.7 \%)$ & $140(30 \%)$ & 0.107 \\
\hline Oral antiplatelet, total & $466(46.5 \%)$ & $177(45.7 \%)$ & $61(40.7 \%)$ & $228(48.9 \%)$ & 0.200 \\
\hline
\end{tabular}

(79.6\% vs. $35.1 \%)$. However, it is important to mention that the sex ratios in the groups differed significantly: women predominated in the HFpEF group, while only $25 \%$ of patients in the HFrEF group were female. Habits and lifestyle were significant for the HFrEF group. Alcohol consumption habits and physical activity level affected the hospitalization frequency. It is interesting that specific symptoms of heart failure were found to be significantly associated with the frequency of rehospitalization for patients with $40 \%$ $<\mathrm{EF}<50 \%$. However, they were not significant for patients with HFmrEF. The predictors related to echocardiographic and clinical characteristics of the cardiovascular status were subdivided into four groups. Presence and signs of persistent hypertension were significant both for the HFpEF and HFrEF subgroups. Signs of old myocardial infarction and concomitant surgeries were significant only for the HFrEF group. Signs of aortic, tricuspid, and pulmonic regurgitations were found to be predictors for HFpEF. Mitral valve dysfunction was the only factor being significant for patients with HFmrEF.

\section{Discussion}

The objective of our survey was to identify the features of the course and management of chronic heart failure in patients with atrial fibrillation and to collect the data on compliance 
TABLE 5: Main outcomes in AF-CHF subgroups.

\begin{tabular}{|c|c|c|c|c|c|}
\hline Endpoints & $\begin{array}{c}\text { Total cohort } \\
(n=1003)\end{array}$ & $\begin{array}{c}\text { AF-HFpEF } \\
(n=387)\end{array}$ & $\begin{array}{c}\text { AF-HFmrEF EF } \\
(n=150)\end{array}$ & $\begin{array}{l}\text { AF-HFrEF } \\
(n=466)\end{array}$ & $p$ level \\
\hline $\begin{array}{l}\text { Hospitalization for worsening of heart } \\
\text { failure }\end{array}$ & $574(57.2 \%)$ & $204(52.7 \%)$ & $99(66 \%)$ & $271(58.2 \%)$ & 0.017 \\
\hline Cardiovascular mortality & $102(10.2 \%)$ & $16(4.1 \%)$ & $14(9.3 \%)$ & $72(15.5 \%)$ & $<0.001$ \\
\hline Thromboembolic events & $34(3.4 \%)$ & $14(3.6 \%)$ & $7(4.7 \%)$ & $13(2.8 \%)$ & 0.451 \\
\hline Ischemic stroke & $27(2.7 \%)$ & $12(3.1 \%)$ & $4(2.7 \%)$ & $11(2.4 \%)$ & 0.776 \\
\hline Myocardial infarct & $101(10.1 \%)$ & $26(6.7 \%)$ & $20(13.3 \%)$ & $55(11.8 \%)$ & 0.014 \\
\hline $\begin{array}{l}\text { Combined point (stroke, IM, and CV } \\
\text { death) }\end{array}$ & $201(17 \%)$ & $49(12.7 \%)$ & $33(22 \%)$ & $119(25.5 \%)$ & $<0.001$ \\
\hline Bleeding rate & $39(3.9 \%)$ & $15(3.9 \%)$ & $7(4.7 \%)$ & $17(3.6 \%)$ & 0.815 \\
\hline
\end{tabular}
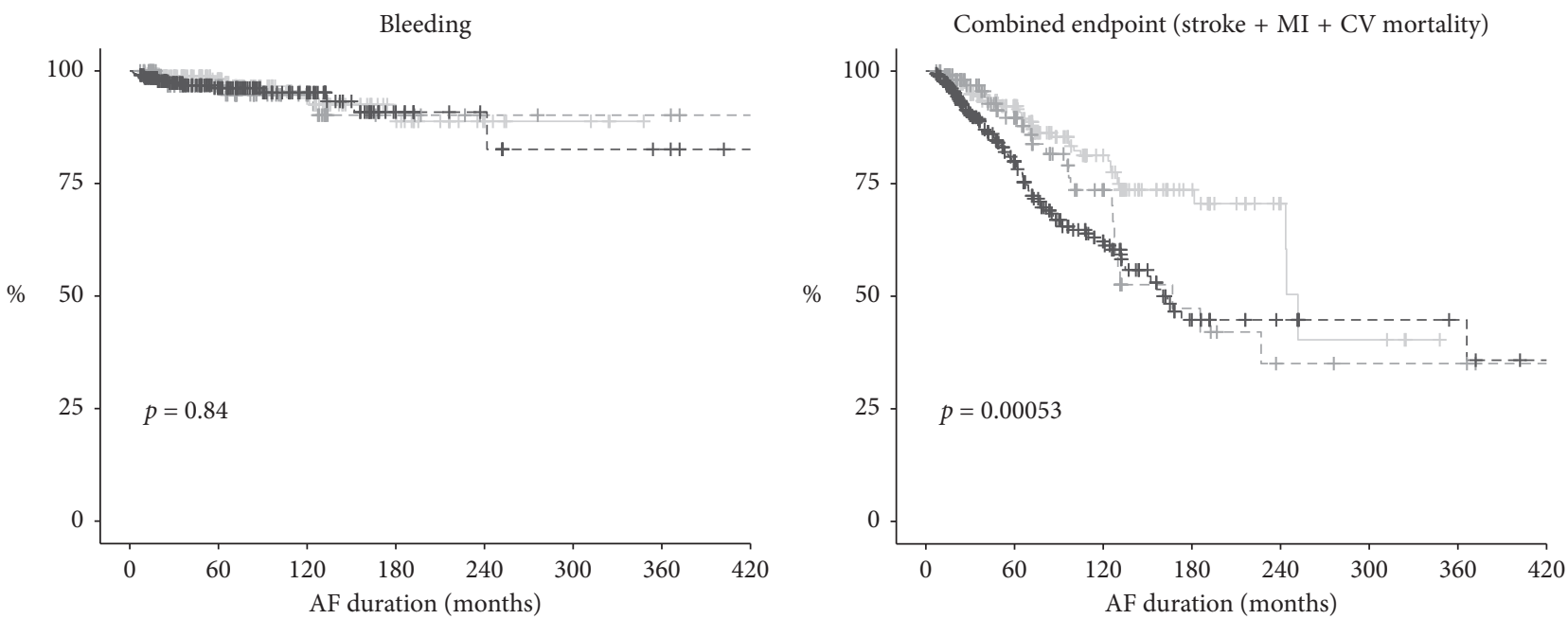

Ejection fraction group

+ $50 \%$ or higher

-+- 40-49\%

- +- Lower than $40 \%$

(a)

Ejection fraction group

+ $50 \%$ or higher

-+- 40-49\%

-+- Lower than $40 \%$

HF hospitalization
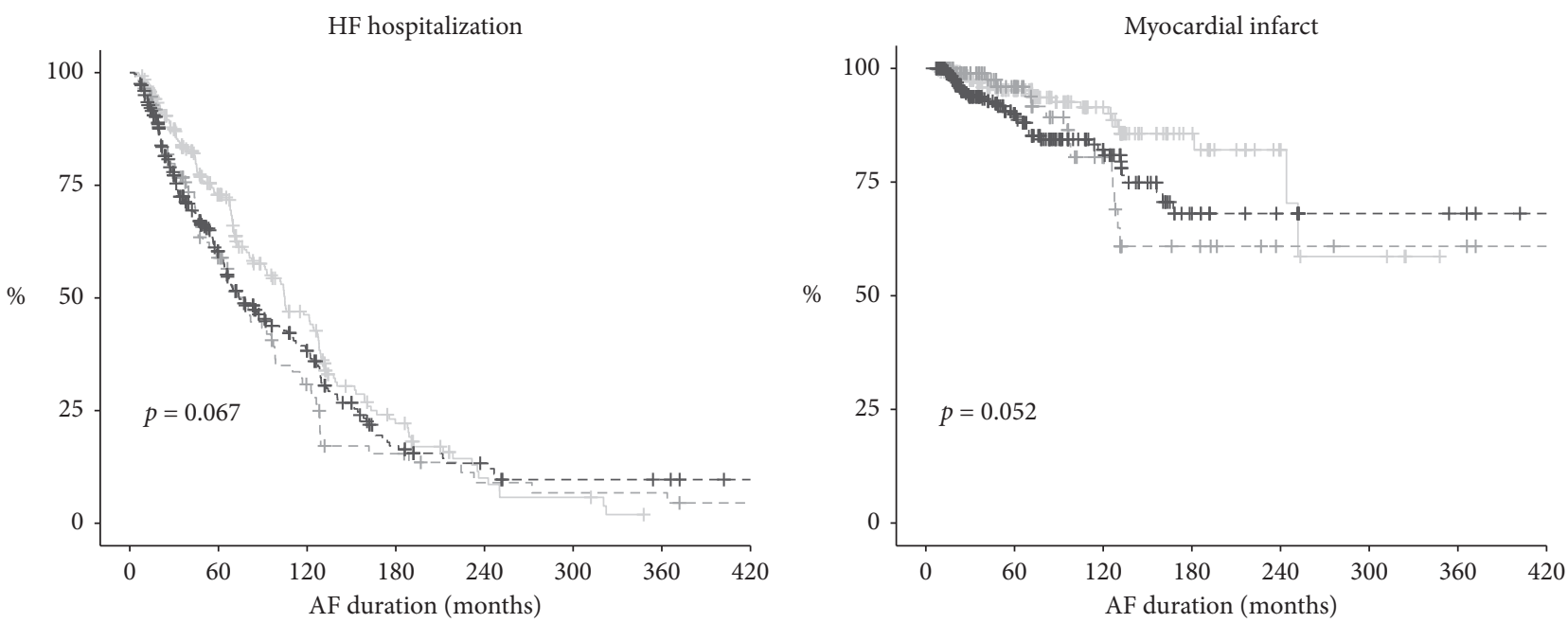

Ejection fraction group

- $50 \%$ or higher

- +- 40-49\%

-+ - Lower than $40 \%$

Ejection fraction group

$-50 \%$ or higher

-+- 40-49\%

-+- Lower than $40 \%$

Figure 2: Continued. 

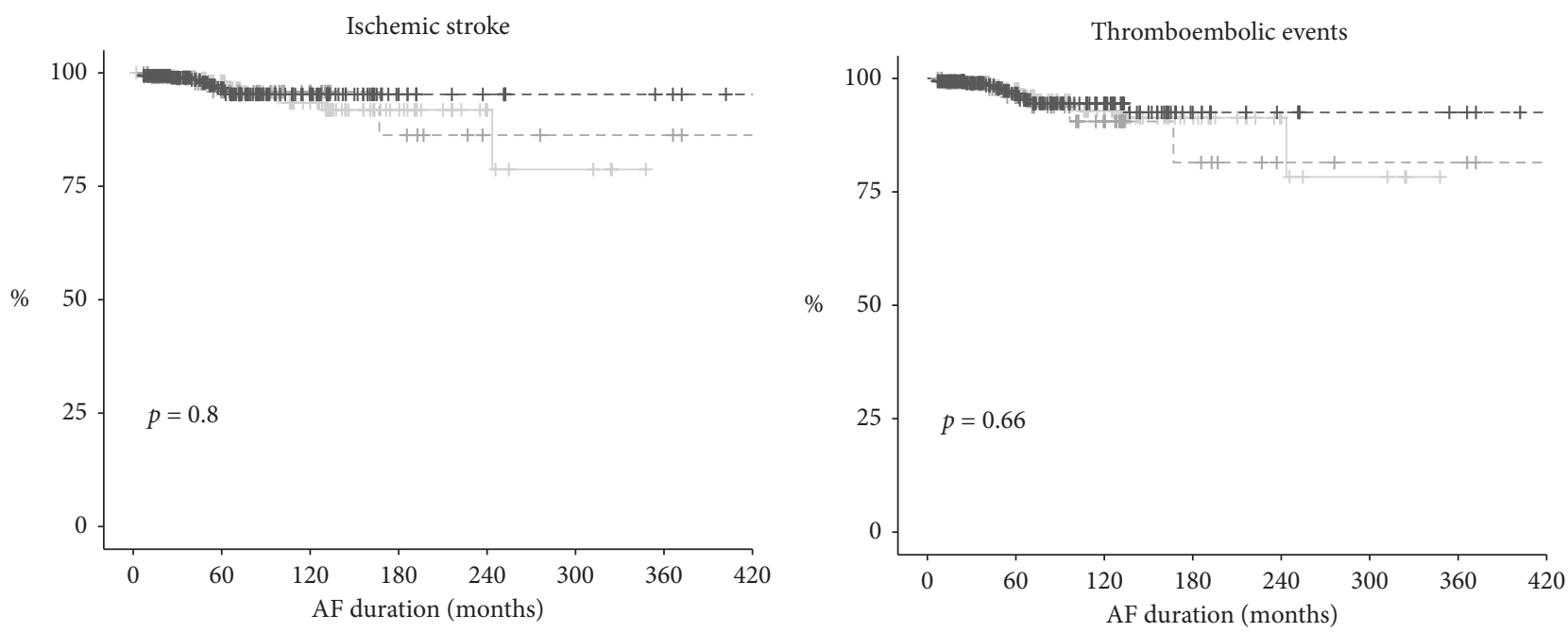

Ejection fraction group

$-50 \%$ or higher

- + - 40-49\%

-+- Lower than $40 \%$

$$
\begin{aligned}
& \text { Ejection fraction group } \\
& -50 \% \text { or higher } \\
& -+-40-49 \% \\
& -+-\quad \text { Lower than } 40 \%
\end{aligned}
$$

(e)

(f)

FIgURE 2: Kaplan-Meier curves for the studied subgroups.

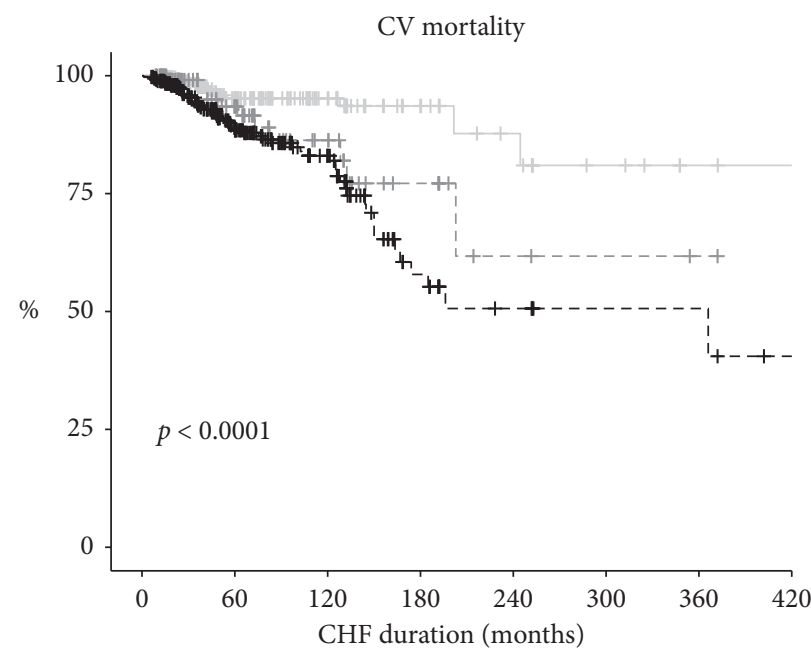

Ejection fraction group $50 \%$ or higher

$-+-40-49 \%$

-+- Lower than $40 \%$

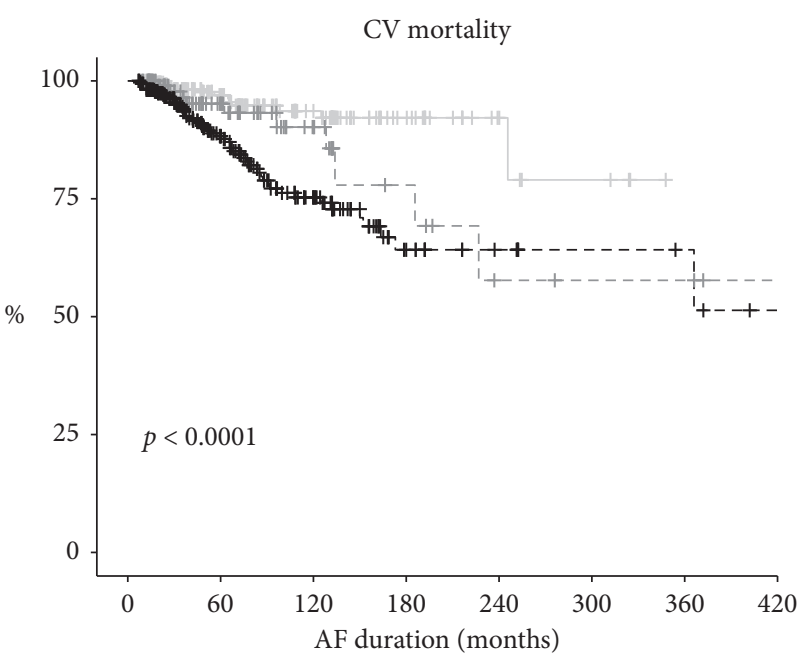

Ejection fraction group

$$
\begin{aligned}
& -50 \% \text { or higher } \\
& -+-40-49 \% \\
& -+- \text { Lower than } 40 \%
\end{aligned}
$$

(b)

Figure 3: CV mortality probability.

with clinical guidelines and on long-term prevalence of this condition in Russia. The primary endpoint in our study was hospitalization because of decompensated heart failure. We demonstrated that the frequency of rehospitalization during the same year was $57.2 \%$. Patients with HFmrEF were hospitalized significantly more often. The mortality, rates of thromboembolic events, and bleeding were selected as secondary endpoints. We found that reduced ejection fraction elevates the risk of cardiovascular mortality, while the risk of ischemic stroke does not increase. Using stroke, myocardial infarction, and $\mathrm{CV}$ mortality as a composite endpoint, we revealed that patients with HFpEF have significantly lower risks as compared to those with HFmrEF and HFrEF.

Several epidemiological studies of heart failure have been carried out in Russia. The largest ones are the EPOKHA- 


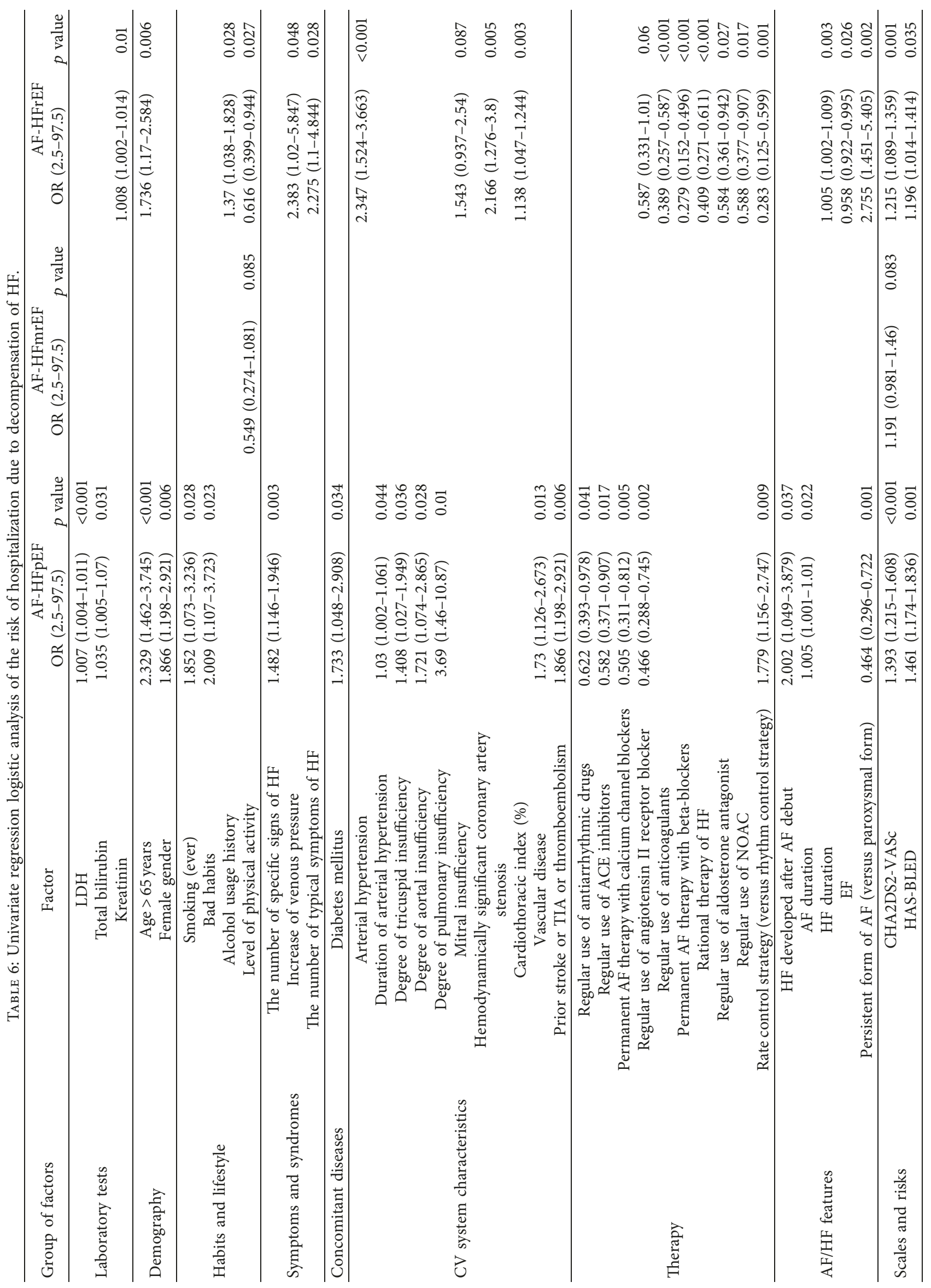




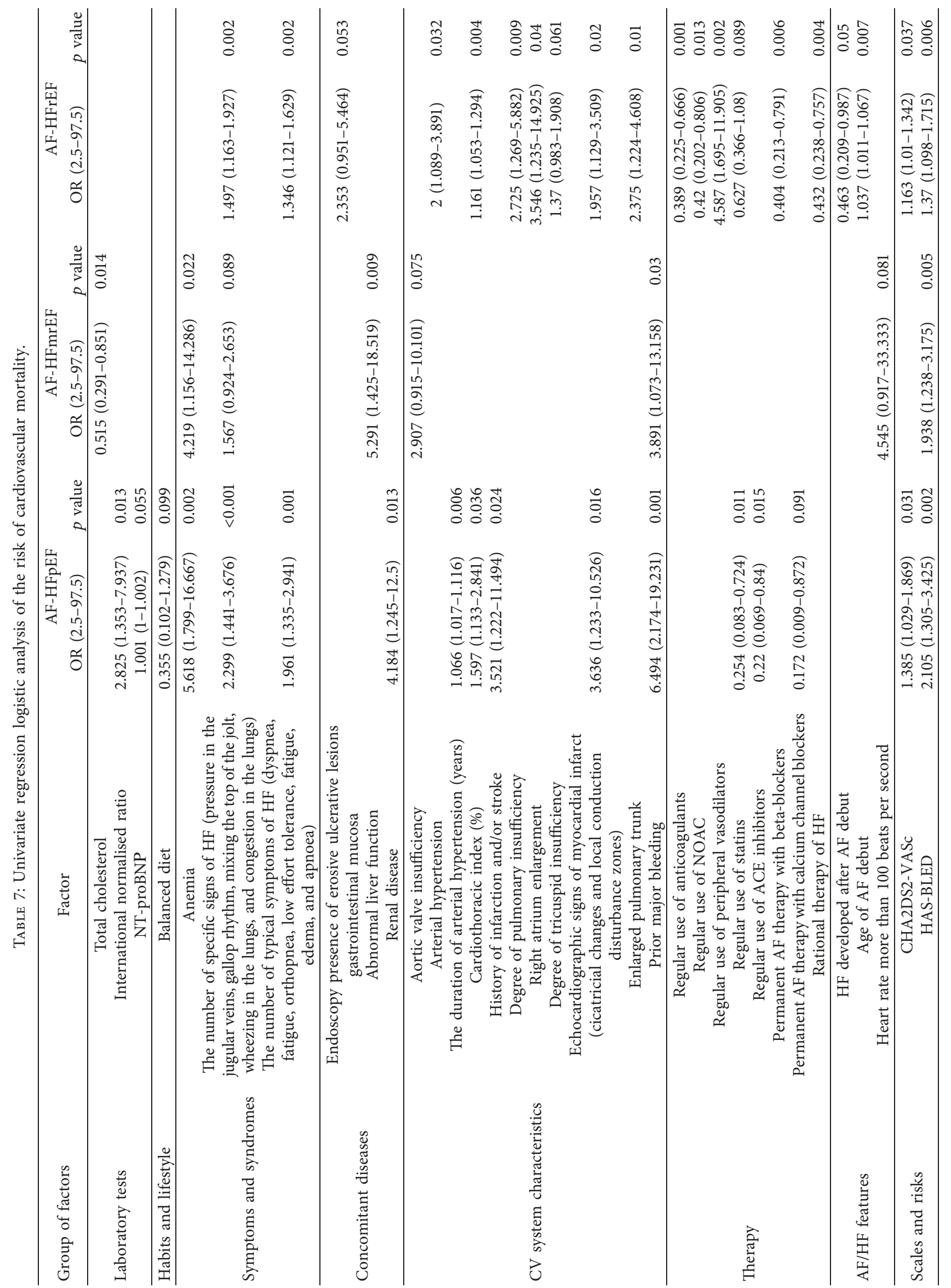




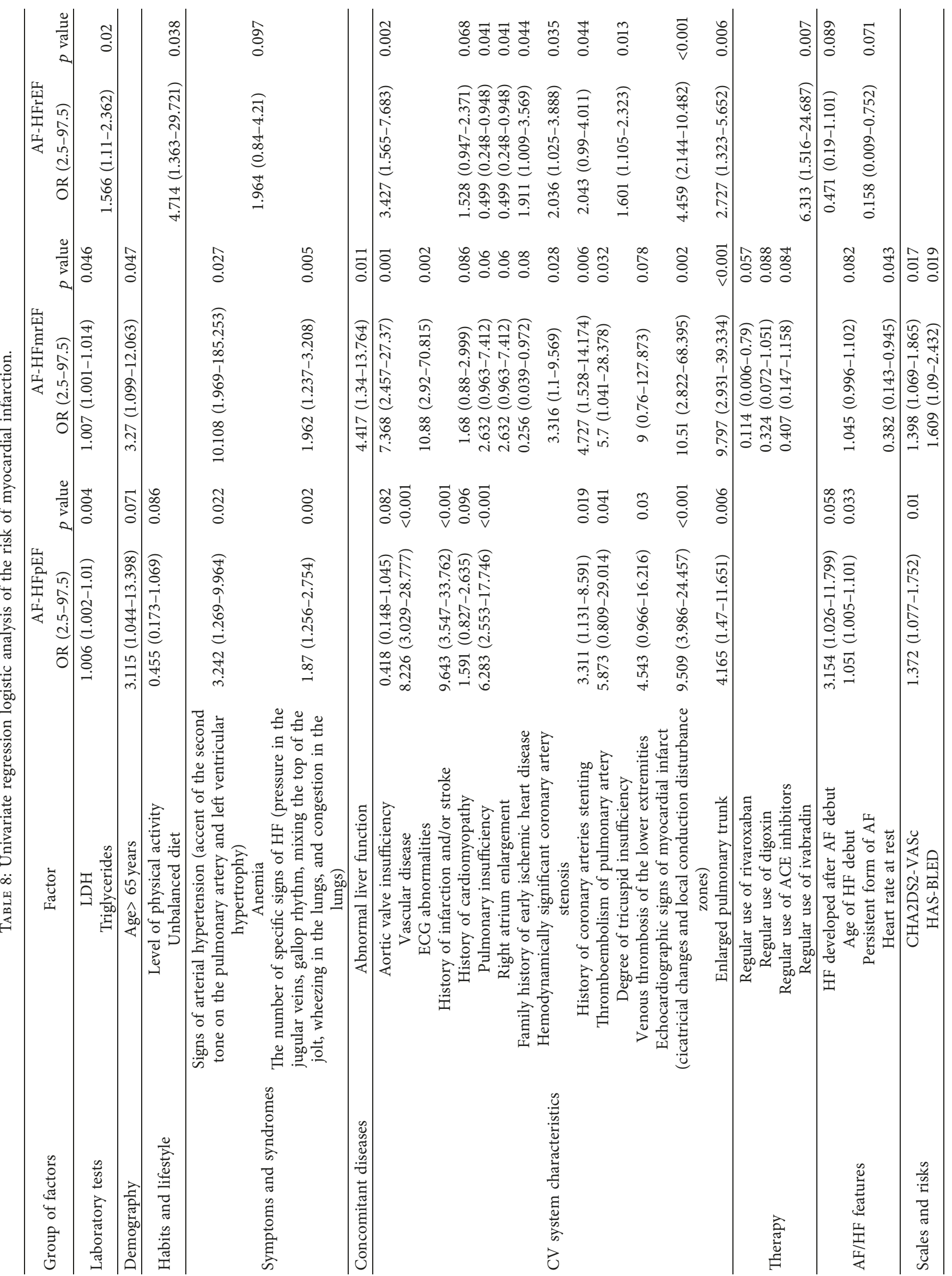


CHF (conducted more than a decade ago) $[32,33]$ and the TOPCAT study $[17,34,35]$. As reported in the EPOKHACHF epidemiological study, the prevalence of CHF in Russia is $11.7 \%$ of the overall population, and $56.8 \%$ of these patients have HFpEF. In our study, only $38.6 \%$ of patients had HFpEF. This fact demonstrates that the AF $+\mathrm{HF}$ comorbidity is characterized by more severe course of HF. In several U.S. community-based samples from 1990 to 2009, we observed divergent trends of decreasing HFrEF and increasing HFpEF incidence, with stable overall HF incidence and high risk for mortality [36]. In our study, the ratio between $\mathrm{AF}-\mathrm{HPrEF}+\mathrm{AF}-\mathrm{HPmrEF}$ vs. AF-HPpEF groups is similar to the ratio in the American cohort. However, in the HPpEF group in our study, women predominate at a ratio of 2 to 1 , and in the study by Tsao et al., there are more men by $20 \%$.

We found that adherence to rational therapy of CHF as well as adherence to anticoagulant therapy is the key factors, reducing the risk of rehospitalization and cardiovascular mortality in patients with HFrEF. However, patients with preserved ejection fraction ( $\mathrm{HFpEF}$ ) were taking aldosterone antagonists almost twice less often. However, even in this group, therapy adherence was significantly higher than that in the Swedish Heart Failure Registry (SwedeHF) [37]. The data on using aldosterone antagonist therapy in AF + HFpEF patients are rather controversial. The TOPCAT trial involving 1,765 patients demonstrated that new-onset AF was not influenced by spironolactone. However, the metaanalysis by Neefs et al. [38] involving 5,332 patients with either existing or new-onset AF showed that aldosterone antagonist therapy reduced the risk of development or recurrence of AF. This conclusion was also valid for the $\mathrm{AF}+\mathrm{HF}$ subgroup. Nevertheless, our findings indicate that patients with AF $+\mathrm{HF}$ comorbidity in Russia are prescribed aldosterone antagonist therapy regardless of ejection fraction. In this study, we found that aldosterone antagonist therapy in the HFrEF group significantly reduced the risk of rehospitalization because of subcompensated HF.

The HFmrEF group differed significantly from the other two groups with respect to the primary endpoint. In this group, the percentage of rehospitalized patients was substantially higher. We revealed that each EF group was characterized by its own factors associated with the primary endpoint.

Therapy received by the patients had a substantial effect on hospitalization frequency. For patients with HFrEF, the most important factor was whether or not they received anticoagulant therapy and its type. Rational therapy (RAS antagonist + beta-blocker + aldosterone blocker) substantially reduced the risk of rehospitalization. In the AF$\mathrm{CHF}$, prospective multicenter trial was found that betablockers were associated with significantly lower mortality but not hospitalizations in patients with $\mathrm{HFrEF}$ and $\mathrm{AF}$, irrespective of the pattern or burden of AF. These results diverged from an individual patient-level meta-analysis conducted by Kotecha et al. [23], which included data from 10 randomized trials of beta-blockers versus placebo in HFrEF. Rienstra et al's main finding of meta-analysis indicates that the effect of beta-blockers in patients with HF and AF is significantly different from the effect of these drugs in patients with HF and sinus rhythm. Indeed, beta-blockers were not found to have a favorable effect on HF hospitalizations or mortality [26].

Therapy subtypes were found to significantly affect the mortality rate only in the HFrEF group. Similar to the primary endpoint, administration of novel oral anticoagulants, adherence to $\beta$-blocker therapy, and rational therapy of $\mathrm{HF}$ reduced the risk of mortality during the one-year follow-up.

Cardiovascular indicators were found to be significantly associated with mortality only for the HFpEF and HFrEF groups but not for HFmrEF patients. The only category of factors that was associated with mortality for all three HF groups included laboratory values attesting to renal insufficiency, anemia, and the BNP level. Furthermore, it was found that chronic kidney disease in HFmrEF patients abruptly increases the risk of mortality.

In our study, we revealed no intergroup differences in thromboembolism. By the time of study initiation, the mean risk of thromboembolism assessed using the CHA2DS2VASc score was significantly higher only in the HFpEF group. This scale was a significant predictor of developing thromboembolism only for this group. An association between HF subtype and thromboembolic events was assessed under actual clinical conditions in the AF-HF substudy of the PREFER trial. The results demonstrated that the HF subtype predicts the residual risk of thromboembolism, and there is an inverse association between LVEF and hard thromboembolic endpoints (ischemic stroke and MACCE).

In this study, we revealed no intergroup difference in the bleeding rate. The low frequency of events did not allow us to analyze the risk factors for bleeding.

Our objective was to study the differences between the EF groups and to identify predictors of unfavorable outcomes using the real-world data. We investigated how the current clinical practice in Russia complies with the international guidelines. The revealed discrepancy was used for the analysis conducted, so that the Russian guidelines could be updated. Our study was the first one in this series and included patients from 23 Russian provinces.

This survey has a number of limitations. Despite the large pool of patients included in it, the groups being compared had some significant baseline differences because of population-wide features of Russian patients. Nevertheless, we have accumulated a large body of real-world data that show the current situation in clinical practice for the local data and can be compared to the data for patients from other countries.

\section{Conclusions}

All three ejection fraction subgroups are characterized by their own features of the course of AF + HF comorbidity; the risks of unfavorable outcomes differ for these subgroups. Reduced ejection fraction increases the risk of cardiovascular mortality but not the risk of thromboembolic events (such as stroke and systemic embolism). Rational therapy of $\mathrm{CHF}$ and adherence to anticoagulant therapy are the key 
factors reducing the risk of rehospitalization and cardiovascular mortality in patients with HFrEF. The rate control strategy has some advantages related to hospitalization because of decompensated CHF for patients with HFrEF, while the rhythm control strategy is beneficial for patients with HFpEF.

\section{Data Availability}

The datasets generated during and/or analyzed during the current study are available from the corresponding author on reasonable request.

\section{Conflicts of Interest}

The authors declare that there are no conflicts of interest regarding the publication of this paper.

\section{Acknowledgments}

We appreciate all Russian local cardiologists for their cooperation and help in organisation of the register: Ageev F. T. (Moscow), Arkhipov M. V. (Ekaterinburg), Barbarash O. L. (Kemerovo), Boldueva S. A. (Saint Petersburg), Borovkova N. Yu. (Nizhny Novgorod), Govorin A. V. (Chita), Golitsyn S. P. (Moscow), Demidov A. A. (Astrakhan), Zubkov S. K. (Smolensk), Kolbasnikov S. V. (Tver), Kuklin S. G. (Irkutsk), Libis R. A. (Orenburg), Matyushin V. G. (Krasnoyarsk), Nevzorova V. A. (Vladivostok), Nedbaykin A. M. (Bryansk), Nikolayeva I. E. (Ufa), Nikulina S. Yu. (Krasnoyarsk), Ostroumova O. D. (Moscow), Stryuk R. I. (Moscow), Urvantseva I. A. (Surgut), Filippenko N. G. (Kursk), Chukayeva I. I. (Moscow), Shalaev S. V. (Tyumen), Schwarz Yu. G. (Saratov), and Shubik Yu. V. (Saint Petersburg).

\section{References}

[1] A. M. Tomlin, H. S. Lloyd, and M. W. Tilyard, "Atrial fibrillation in New Zealand primary care: prevalence, risk factors for stroke and the management of thromboembolic risk," European Journal of Preventive Cardiology, vol. 24, no. 3, pp. 311-319, 2017.

[2] J. M. Siller-Matula, L. Pecen, G. Patti et al., "Heart failure subtypes and thromboembolic risk in patients with atrial fibrillation: the PREFER in AF-HF substudy," International Journal of Cardiology, vol. 265, pp. 141-147, 2018.

[3] W. H. Maisel and L. W. Stevenson, "Atrial fibrillation in heart failure: epidemiology, pathophysiology, and rationale for therapy," American Journal of Cardiology, vol. 91, no. 1, pp. 2-8, 2003.

[4] R. Zakeri, A. M. Chamberlain, V. L. Roger, and M. M. Redfield, "Temporal relationship and prognostic significance of atrial fibrillation in heart failure patients with preserved ejection fraction," Circulation, vol. 128, no. 10, pp. 1085-1093, 2013.

[5] R. B. Patel, M. Vaduganathan, S. J. Shah, and J. Butler, "Atrial fibrillation in heart failure with preserved ejection fraction: insights into mechanisms and therapeutics," Pharmacology \& Therapeutics, vol. 176, pp. 32-39, 2017.

[6] V. M. Van Deursen, R. Urso, C. Laroche et al., et al., "Comorbidities in patients with heart failure: an analysis of the
European Heart Failure Pilot Survey," European Journal of Heart Failure, vol. 16, no. 1, pp. 103-111, 2014.

[7] P. Ponikowski, A. A. Voors, S. D. Anker et al., "2016 ESC Guidelines for the diagnosis and treatment of acute and chronic heart failure," European Heart Journal, vol. 37, no. 27, pp. 2129-2200, 2016.

[8] P. Kirchhof, S. Benussi, D. Kotecha et al., "ESC Guidelines for the management of atrial fibrillation developed in collaboration with EACTS," European Heart Journal, vol. 37, no. 38, 2016.

[9] F. Braunschweig, M. R. Cowie, and A. Auricchio, "What are the costs of heart failure?," Europace, vol. 13, no. 2, pp. 13-17, 2011.

[10] W. P. Wodchis, R. S. Bhatia, K. Leblanc, N. Meshkat, and D. Morra, "A review of the cost of atrial fibrillation," Value in Health, vol. 15, no. 2, pp. 240-248, 2012.

[11] R. Santhanakrishnan, N. Wang, M. G. Larson et al., "Atrial fibrillation begets heart failure and vice versa," Circulation, vol. 133, no. 5, pp. 484-492, 2016.

[12] M. D. Smit, M. L. Moes, A. H. Maass et al., "The importance of whether atrial fibrillation or heart failure develops first," European Journal of Heart Failure, vol. 14, no. 9, pp. 10301040, 2012.

[13] T. Takagi, N. Satake, and S. Shibata, "The inhibitory action of FR 34235 (A new $\mathrm{Ca}^{2+}$ entry blocker) as compared to nimodipine and nifedipine on the contractile response to norepinephrine, potassium and 5-hydroxytryptamine in rabbit basilar artery," European Journal of Pharmacology, vol. 90, no. 2-3, pp. 297-299, 1983.

[14] U. C. Hoppe, J. M. Casares, H. Eiskjær et al., "Effect of cardiac resynchronization on the incidence of atrial fibrillation in patients with severe heart failure," Circulation, vol. 114, no. 1, pp. 18-25, 2006.

[15] M. Senni, W. J. Paulus, A. Gavazzi et al., "New strategies for heart failure with preserved ejection fraction: the importance of targeted therapies for heart failure phenotypes," European Heart Journal, vol. 35, no. 40, pp. 2797-2815, 2014.

[16] P. Goyal, Z. I. Almarzooq, J. Cheung et al., "Atrial fibrillation and heart failure with preserved ejection fraction: insights on a unique clinical phenotype from a nationally-representative United States cohort," International Journal of Cardiology, vol. 266, pp. 112-118, 2018.

[17] M. Cikes, B. Claggett, A. M. Shah et al., "Atrial fibrillation in heart failure with preserved ejection fraction," JACC: Heart Failure, vol. 6, no. 8, pp. 689-697, 2018.

[18] C. S. P. Lam, M. Rienstra, W. T. Tay et al., "Atrial fibrillation in heart failure with preserved ejection fraction," JACC: Heart Failure, vol. 5, no. 2, pp. 92-98, 2017.

[19] Y. Sobue, E. Watanabe, G. Y. H. Lip et al., "Thromboembolisms in atrial fibrillation and heart failure patients with a preserved ejection fraction (HFpEF) compared to those with a reduced ejection fraction (HFrEF)," Heart and Vessels, vol. 33, no. 4, pp. 403-412, 2017.

[20] Q. Xiong, Y. C. Lau, K. Senoo, D. A. Lane, K. Hong, and G. Y. H. Lip, "Non-vitamin K antagonist oral anticoagulants (NOACs) in patients with concomitant atrial fibrillation and heart failure: a systemic review and meta-analysis of randomized trials," European Journal of Heart Failure, vol. 17, no. 11, pp. 1192-1200, 2015.

[21] A. Odutayo, C. X. Wong, A. J. Hsiao, S. Hopewell, D. G. Altman, and C. A. Emdin, "Atrial fibrillation and risks of cardiovascular disease, renal disease, and death: systematic review and meta-analysis," BMJ, vol. 354, article i4482, 2016. 
[22] D. Kotecha, R. Chudasama, D. A. Lane, P. Kirchhof, and G. Y. H. Lip, "Atrial fibrillation and heart failure due to reduced versus preserved ejection fraction: a systematic review and meta-analysis of death and adverse outcomes," International Journal of Cardiology, vol. 203, pp. 660-666, 2016.

[23] D. Kotecha, J. Holmes, H. Krum et al., "Efficacy of $\beta$ blockers in patients with heart failure plus atrial fibrillation: an individual-patient data meta-analysis," The Lancet, vol. 384, no. 9961, pp. 2235-2243, 2014.

[24] V. Ruddox, I. Sandven, J. Munkhaugen, J. Skattebu, T. Edvardsen, and J. E. Otterstad, "Atrial fibrillation and the risk for myocardial infarction, all-cause mortality and heart failure: a systematic review and meta-analysis," European Journal of Preventive Cardiology, vol. 24, no. 14, pp. 1555-1566, 2017.

[25] C. A. Emdin, C. X. Wong, A. J. Hsiao et al., "Atrial fibrillation as risk factor for cardiovascular disease and death in women compared with men: systematic review and meta-analysis of cohort studies," BMJ, 2016.

[26] M. Rienstra, K. Damman, B. A. Mulder, I. C. Van Gelder, J. J. V. McMurray, and D. J. Van Veldhuisen, "Beta-blockers and outcome in heart failure and atrial fibrillation," JACC: Heart Failure, vol. 1, no. 1, pp. 21-28, 2013.

[27] M. Cheng, X. Lu, J. Huang, J. Zhang, S. Zhang, and D. Gu, "The prognostic significance of atrial fibrillation in heart failure with a preserved and reduced left ventricular function: insights from a meta-analysis," European Journal of Heart Failure, vol. 16, no. 12, pp. 1317-1322, 2014.

[28] T. S. Cherian, P. Shrader, G. C. Fonarow et al., "Effect of atrial fibrillation on mortality, stroke risk, and quality-of-life scores in patients with heart failure (from the outcomes Registry for better informed treatment of atrial fibrillation [ORBIT-AF])," American Journal of Cardiology, vol. 119, no. 11, pp. 1763$1769,2017$.

[29] S. Goto, D. L. Bhatt, J. Röther et al., "Prevalence, clinical profile, and cardiovascular outcomes of atrial fibrillation patients with atherothrombosis," American Heart Journal, vol. 156, no. 5, pp. 855-863.e2, 2008.

[30] U. Sartipy, U. Dahlström, M. Fu, and L. H. Lund, "Atrial fibrillation in heart failure with preserved, mid-range, and reduced ejection fraction," JACC: Heart Failure, vol. 5, no. 8, pp. 565-574, 2017.

[31] J.-P. Bassand, G. Accetta, A. J. Camm et al., "Two-year outcomes of patients with newly diagnosed atrial fibrillation: results from GARFIELD-AF," European Heart Journal, vol. 37, no. 38, pp. 2882-2889, 2016.

[32] Y. Belenkov, V. Mareev, F. Ageev, and M. Danielyan, "First results of national Russian epidemiological studyepidemiological examination of patients with $\mathrm{CHF}$ in realworld data-(EPOKHA-O-CHF)," Russian Heart Failure Journal (Serdechnaya Nedostatochnost'), vol. 4, no. 3, pp. 116-121, 2004.

[33] Y. Belenkov, I. Fomin, and V. Mareev, "First results of Russian epidemiological study of chronic heart failure (EPOKHACHF)," Russian Heart Failure Journal (Serdechnaya Nedostatochnost'), vol. 4, no. 1, pp. 26-30, 2003.

[34] M. A. Pfeffer, B. Claggett, S. F. Assmann et al., "Regional variation in patients and outcomes in the treatment of preserved cardiac function heart failure with an aldosterone antagonist (TOPCAT) trial," Circulation, vol. 131, no. 1, pp. 34-42, 2015.

[35] A. S. Desai, E. F. Lewis, R. Li et al., "Rationale and design of the treatment of preserved cardiac function heart failure with an aldosterone antagonist trial: a randomized, controlled study of spironolactone in patients with symptomatic heart failure and preserved ejection fraction," American Heart Journal, vol. 162, no. 6, pp. 966-972, 2011.

[36] C. W. Tsao, A. Lyass, D. Enserro et al., "Temporal trends in the incidence of and mortality associated with heart failure with preserved and reduced ejection fraction," JACC: Heart Failure, vol. 6, no. 8, pp. 678-685, 2018.

[37] J. Cadrin-Tourigny, A. Shohoudi, D. Roy et al., et al., "Decreased mortality with beta-blockers in patients with heart failure and coexisting atrial fibrillation," JACC: Heart Failure, vol. 5, no. 2, pp. 99-106, 2017.

[38] J. Neefs, N. W. E. van den Berg, J. Limpens et al., et al., "Aldosterone pathway blockade to prevent atrial fibrillation: a systematic review and meta-analysis," International Journal of Cardiology, vol. 231, pp. 155-161, 2017. 


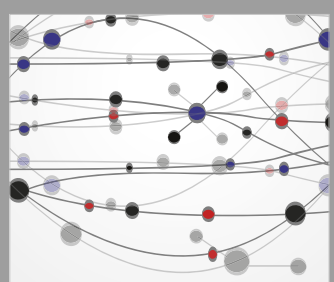

The Scientific World Journal
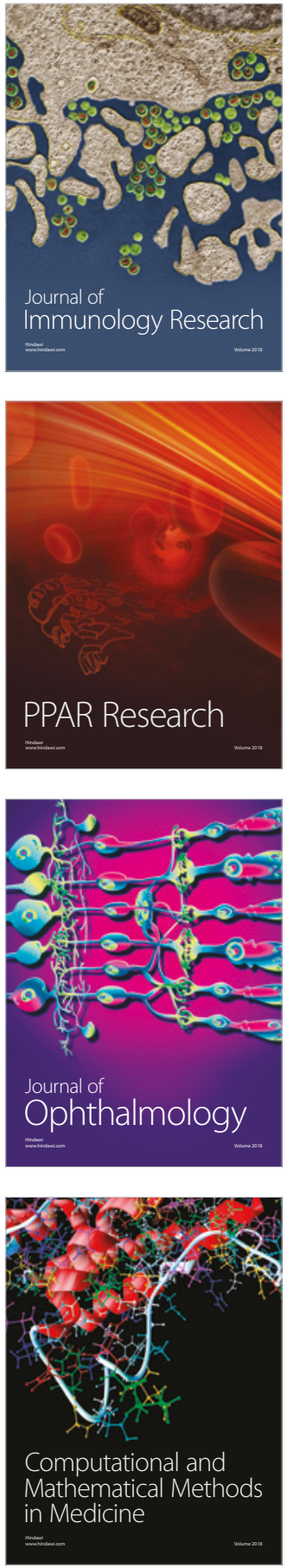

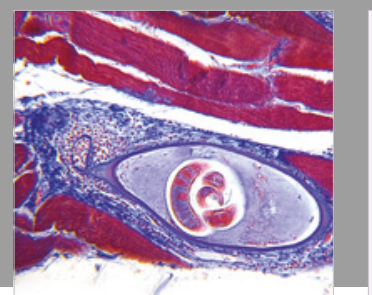

Gastroenterology Research and Practice

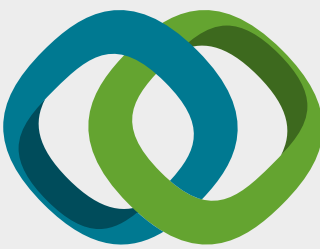

\section{Hindawi}

Submit your manuscripts at

www.hindawi.com
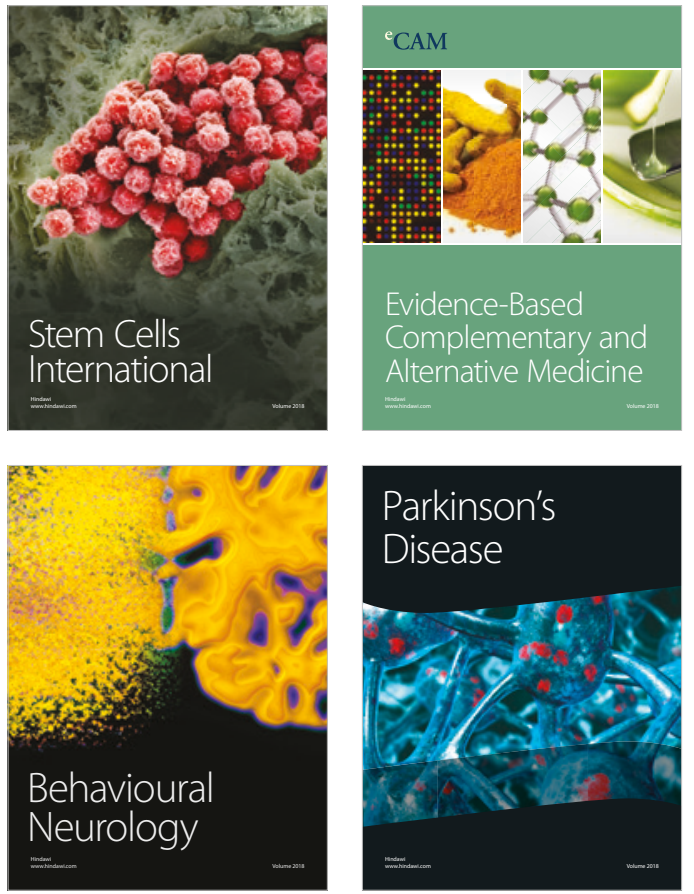

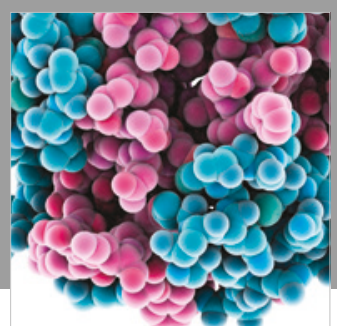

ournal of

Diabetes Research

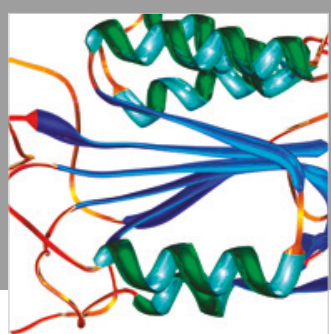

Disease Markers
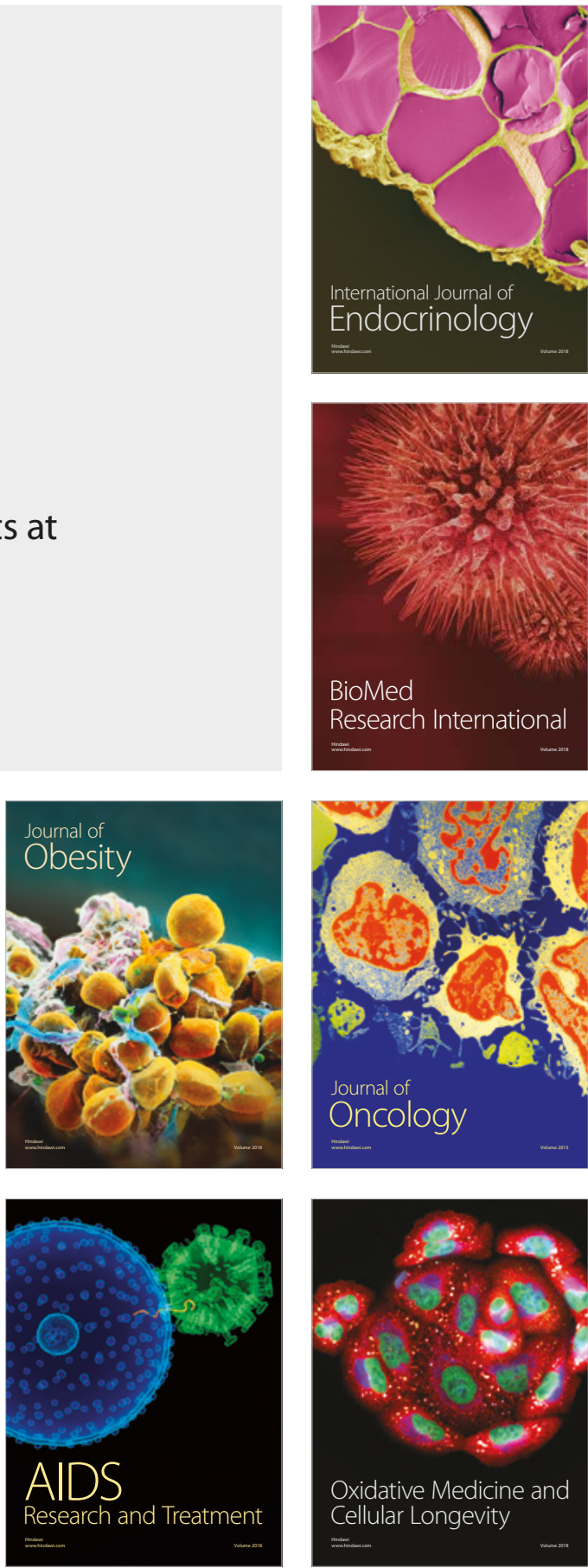